\title{
Prevalence and correlates for psychosocial distress among in-school adolescents in Zambia
}

\author{
Seter Siziya ${ }^{1,2 *}$ and Mazyanga Lucy Mazaba ${ }^{3,4}$ \\ ${ }^{1}$ Department of Clinical Sciences, School of Medicine, Copperbelt University, Ndola, Zambia, ${ }^{2}$ Department of Public Health, \\ School of Health Sciences, University of Lusaka, Lusaka, Zambia, ${ }^{3}$ Immune and Vaccine Preventable Diseases, World Health \\ Organization, Lusaka, Zambia, ${ }^{4}$ Virology Unit, University Teaching Hospital, Ministry of Health, Lusaka, Zambia
}

\section{OPEN ACCESS}

Edited by: Hatim A. Omar

University of Kentucky, USA

Reviewed by: John Andrew Yozwiak University of Kentucky, USA Marlene Belew Huff,

University of Kentucky, USA

*Correspondence: Seter Siziya, Department of Clinical Sciences,

School of Medicine,

Copperbelt University, P O Box 71191, Ndola 10101,

Zambia

ssiziya@gmail.com

Specialty section:

This article was submitted to Child Health and Human Development, a section of the journal Frontiers in Public Health

Received: 03 June 2015 Accepted: 29 June 2015 Published: 16 July 2015

Citation:

Siziya S and Mazaba ML (2015) Prevalence and correlates for psychosocial distress among in-school adolescents in Zambia.

Front. Public Health 3:180. doi: 10.3389/fpubh.2015.00180
There is scanty information on correlates for psychosocial distress in Zambia. Secondary analysis was conducted using the data collected in 2004 in Zambia during the global school-based health survey to determine the prevalence and correlates for psychosocial distress. Logistic regression analyses were used to estimate magnitudes of associations between exposure factors and the outcome, while the Yates' corrected Chi-squared test was used to compare proportions at the 5\% significance level. A total of 2257 students participated in the survey of which $54.2 \%$ were males. Males were generally older than females $(p<0.001)$. Significantly, more females than males were bullied $(p=0.036)$, involved in a fight $(p=0.019)$, and consumed alcohol $(p=0.012)$. Psychosocial distress was detected in $15.7 \%$ of the participants (14.4\% of males and $16.8 \%$ of females). Age $<14$ years, male gender, parental support for males, and having close friends were protective factors against psychosocial distress. Risk factors for psychosocial distress were being bullied, involvement in a fight, alcohol consumption, being physically active, and parental support. The prevalence of psychosocial distress among adolescents in Zambia appears to be common. There is a need to validate the psychosocial distress indicators that were used in the current study.

Keywords: psychosocial distress, social support, physical activity, alcohol, violence, adolescents, Zambia

\section{Introduction}

Psychosocial distress is a common health problem worldwide with varying rates (1) and it starts during childhood and adolescent (2). Prevalence rates for psychosocial distress varied between studies partly because different studies used different definitions for psychosocial distress. In some studies, psychosocial distress was assessed using four mental health indicators: loneliness, anxiety or worried, sadness, and suicide plan $(3,4)$. In another study, Hong et al. (5) defined psychosocial distress using five indicators: alcohol intoxication, drug use, suicidal behavior, depression, and loneliness. In yet another study, psychosocial distress was defined as a composite measure of depression, self-perceived stress, neuroticism, and dissatisfaction (6). Stevenson et al. (7) calculated the score for psychosocial distress by summing each respondent's answers to the 29 SRQF questions. In a school-based survey in Iran, psychosocial distress was detected in $71.2 \%$ of boys and $63.3 \%$ of girls (8). Meanwhile, rates of $2.0 \%$ among boys and $3.0 \%$ among girls have been reported in Thailand (9).

Protective factors associated with psychosocial distress include living with both parents and good parent-teen connectedness. Risk factors for distress include having sex with two or more sex 
partners and substance use. In a study in Ethiopia in which $93 \%$ of the students were of age 15-19 years, Shiferaw et al. (10) found that living with both biological parents and good parent-teen connectedness were related to better psychosocial health. Page and Hall (4) reported that psychosocial distress was associated with having sex or having sex with two or more people among adolescents in subSaharan African countries including Botswana, Kenya, Namibia, Uganda, Zambia, and Zimbabwe. Using data obtained in Global School-Based Student Health Surveys in Philippines, China, Chile, and Namibia, Page et al. (11) found that adolescent substance use (lifetime use of alcohol, tobacco, and other drugs) was a risk factor for psychosocial distress.

There is scanty information on the correlates for psychosocial distress in Zambia, and the present study was aimed to determine the prevalence and correlates for psychosocial distress among in-school adolescents in order to contribute to the knowledge base for use to design interventions to curb this psychosocial problem among adolescents. Since the study was exploratory, no hypotheses could be tested and hoped that hypotheses could be generated from this study.

\section{Materials and Methods}

Secondary analysis was conducted using the data (12) collected in 2004 in Zambia during the global school-based health survey (GSHS). A detailed description of the GSHS methodology that was used in Zambia is described elsewhere (13). The GSHS was developed by the World Health Organization (WHO) in collaboration with UNICEF, UNESCO, and UNAIDS with technical assistance from CDC, Atlanta, GA, USA. The main purpose of the GSHS is to obtain health and social behavioral data primarily among 13- to 15-year-old school-going adolescents. In Zambia, this age group was mostly in grades 7-10. Participants were randomly selected using a two-stage cluster sampling technique. In the first stage of sampling, 50 schools were randomly selected from 4621 government schools with probability proportional to their enrollment size. A total of 47 schools participated in the survey, giving a school response rate of $94 \%$. At the second stage of sampling, classes were randomly selected and all students in selected classes irrespective of their ages were requested to participate in the survey. Out of 3021 eligible students, 2257 students participated in the survey giving a student response rate of $75 \%$. The overall response rate was $70 \%$.

\section{Ethical Considerations}

Ethical review and approval was granted by the Ministries of Health and Education. Permission to collect the data from the students was obtained from head teachers. Students were informed that they were free not to participate in the survey, and that they were free not to answer some questions or withdraw from the survey if they chose to participate the survey. The questionnaire did not have personal identifiers. Teachers were excused from classes during the administration of the questionnaire and did not have access to completed questionnaires.

\section{Data Collection}

Data were collected using a modified GSHS questionnaire. The 54 core questions in the GSHS questionnaire were on age, sex, weight, height, dietary behavior, household food security, personal hygiene, water, physical violence, injuries, bullying, personal safety, feelings, and friendship. The Zambia GSHS questionnaire also included 35 questions on alcohol abuse, drug abuse, sexual behavior and HIV/AIDS, physical activity, leisure time, and experiences at school (14). The questionnaire was filled-in by the students by recording their responses directly on a computerscannable response sheet.

\section{Variables}

The outcome variable "Psychosocial distress" was assessed using four mental health indicators: loneliness, anxiety or worried, sadness, and suicide plan based on previous research on a similar school-going adolescent population (9). A respondent with three or four of the four mental health indicators was declared as having psychosocial distress. The independent variables were age, sex, bullied, fight, alcohol, activity, parental support and supervision, and friendship. Table 1 shows the variables that were considered in the analysis.

\section{Data Analysis}

A Statistical Package for Social Sciences (SPSS) version 17.0 was used in the analysis. Weighted analyses were conducted using the following weights in order to account for differences in response rates:

$$
\mathrm{W}=\mathrm{W} 1 * \mathrm{~W} 1 * \mathrm{f} 1 * \mathrm{f} 2 * \mathrm{f} 3 * \mathrm{f} 4
$$

where $\mathrm{W} 1=$ the inverse of the probability of selecting the school, $\mathrm{W} 2=$ the inverse of the probability of selecting the classroom within the school, $\mathrm{fl}=\mathrm{a}$ school-level non-response adjustment factor calculated by school size category (small, medium, large), $\mathrm{f} 2$ = a class-level non-response adjustment factor calculated for each school, $\mathrm{f} 3=$ a student-level non-response adjustment factor calculated by class, and $\mathrm{f} 4=$ a post stratification adjustment factor calculated by grade.

Proportions were compared using the Yates' corrected Chisquared test in $2 \times 2$ tables and the Pearson's Chi-squared test was used in higher contingency tables. The level of statistical significance was set at the 5\% level. Logistic regression analyses were conducted using a backward variable selection method to determine associations between selected independent variables and psychosocial distress. Unadjusted odds ratios (OR) and adjusted odds ratios (AOR) together with their 95\% confidence intervals (CI) were used to estimate magnitudes of associations.

\section{Results}

A total of 2257 students participated in the survey of which $54.2 \%$ were males. About one-third (30.4\%) of the participants were of age 16 years or older. Males were generally older than females $(p<0.001)$ with $61.3 \%$ of males and $48.3 \%$ of females being of age 15 years or older. Psychosocial distress was detected in $15.7 \%$ of the participants ( $14.4 \%$ of males and $16.8 \%$ of females). These results are shown in Table 2.

Tables 3 and 4 show factors that were associated with psychosocial distress. In bivariate analyses, all the factors that were considered in the analysis were significantly associated with psychosocial distress. Male participants were $2 \%(\mathrm{AOR}=0.8,95 \% \mathrm{CI}$ 
TABLE 1 | Variables considered in the analysis.

\begin{tabular}{|c|c|c|c|}
\hline Variable & Description/question & Coded & Recoded \\
\hline \multicolumn{4}{|l|}{ Dependent } \\
\hline $\begin{array}{l}\text { Psychosocial } \\
\text { distress }\end{array}$ & Assessed using four mental health measures & $0-4$ & $\begin{array}{l}1=3 \text { or } 4 \\
0 \leq 3\end{array}$ \\
\hline Loneliness & During the past 12 months, how often have you felt lonely? & $\begin{array}{l}1=\text { Never } \\
2=\text { Rarely } \\
3=\text { Sometimes } \\
4=\text { Most of the time } \\
5=\text { Always }\end{array}$ & $\begin{array}{l}1=\text { Most of the time or always } \\
2=\text { Never, rarely or sometimes }\end{array}$ \\
\hline Worried & $\begin{array}{l}\text { During the past } 12 \text { months, how often have you been so worried about } \\
\text { something that you could not sleep at night? }\end{array}$ & $\begin{array}{l}1=\text { Never } \\
2=\text { Rarely } \\
3=\text { Sometimes } \\
4=\text { Most of the time } \\
5=\text { Always }\end{array}$ & $\begin{array}{l}1=\text { Most of the time or always } \\
2=\text { Never, rarely or sometimes }\end{array}$ \\
\hline Sadness & $\begin{array}{l}\text { During the past } 12 \text { months, did you ever feel so sad or hopeless almost every } \\
\text { day for } 2 \text { weeks or more in a row that you stopped doing your usual activities? }\end{array}$ & $\begin{array}{l}1=\text { Yes } \\
2=\text { No }\end{array}$ & $\begin{array}{l}1=\text { Yes } \\
2=\text { No }\end{array}$ \\
\hline Suicide plan & $\begin{array}{l}\text { During the past } 12 \text { months, did you make a plan about how you would } \\
\text { attempt suicide? }\end{array}$ & $\begin{array}{l}1=\text { Yes } \\
2=\text { No }\end{array}$ & $\begin{array}{l}1=\text { Yes } \\
2=\text { No }\end{array}$ \\
\hline \multicolumn{4}{|l|}{ Independent } \\
\hline Age & How old are you? & $\begin{array}{l}1=11 \text { years old or younger } \\
2=12 \text { years old } \\
3=13 \text { years old } \\
4=14 \text { years old } \\
5=15 \text { years old } \\
6=16 \text { years or older }\end{array}$ & $\begin{array}{l}1=14 \text { years or younger } \\
2=14 \text { years } \\
3=15 \text { years } \\
4=16 \text { years or older }\end{array}$ \\
\hline Sex & What is your sex? & $\begin{array}{l}1=\text { Male } \\
2=\text { Female }\end{array}$ & $\begin{array}{l}1=\text { Male } \\
2=\text { Female }\end{array}$ \\
\hline Bullied & During the past 30 days, on how many days were you bullied? & $\begin{array}{l}1=0 \text { days } \\
2=1-2 \text { days } \\
3=3-5 \text { days } \\
4=6-9 \text { days } \\
5=10-19 \text { days } \\
6=20-29 \text { days } \\
7=\text { All } 30 \text { days }\end{array}$ & $\begin{array}{l}1=1-30 \text { days } \\
2=0 \text { days }\end{array}$ \\
\hline Fight & During the past 12 months, how many times were you in a physical fight? & $\begin{array}{l}1=0 \text { times } \\
2=1 \text { time } \\
3=2 \text { or } 3 \text { times } \\
4=4 \text { or } 5 \text { times } \\
5=6 \text { or } 7 \text { times } \\
6=8 \text { or } 9 \text { times } \\
7=10 \text { or } 11 \text { times } \\
8=12 \text { or more times }\end{array}$ & $\begin{array}{l}1=1 \text { or more times } \\
2=0 \text { times }\end{array}$ \\
\hline Alcohol & $\begin{array}{l}\text { During the past } 30 \text { days, on how many days did you have at least one drink } \\
\text { containing alcohol? }\end{array}$ & $\begin{array}{l}1=0 \text { days } \\
2=1 \text { or } 2 \text { days } \\
3=3-5 \text { days } \\
4=6-9 \text { days } \\
5=10-19 \text { days } \\
6=20-29 \text { days } \\
7=\text { All } 30 \text { days }\end{array}$ & $\begin{array}{l}1=1 \text { or more days } \\
2=0 \text { days }\end{array}$ \\
\hline Activity & $\begin{array}{l}\text { During the past } 7 \text { days, on how many days were you physically active for a } \\
\text { total of at least } 60 \text { minutes per day? }\end{array}$ & $\begin{array}{l}1=0 \text { days } \\
2=1 \text { day } \\
3=2 \text { days } \\
4=3 \text { days } \\
5=4 \text { days } \\
6=5 \text { days } \\
7=6 \text { days } \\
8=7 \text { days }\end{array}$ & $\begin{array}{l}1=4-7 \text { days } \\
2<4 \text { days }\end{array}$ \\
\hline
\end{tabular}


TABLE 1 | Continued

\begin{tabular}{|c|c|c|c|}
\hline Variable & Description/question & Coded & Recoded \\
\hline $\begin{array}{l}\text { Parental } \\
\text { supervision }\end{array}$ & $\begin{array}{l}\text { During the past } 30 \text { days, how often did your parents or guardians really know } \\
\text { what you were doing with your free time? }\end{array}$ & $\begin{array}{l}1=\text { Never } \\
2=\text { Rarely } \\
3=\text { Sometimes } \\
4=\text { Most of the time } \\
5=\text { Always }\end{array}$ & $\begin{array}{l}1=\text { Most of the time or always } \\
2=\text { Never, rarely or sometimes }\end{array}$ \\
\hline Parental support & $\begin{array}{l}\text { During the past } 30 \text { days, how often did your parents or guardians understand } \\
\text { your problems and worries? }\end{array}$ & $\begin{array}{l}1=\text { Never } \\
2=\text { Rarely } \\
3=\text { Sometimes } \\
4=\text { Most of the time } \\
5=\text { Always }\end{array}$ & $\begin{array}{l}1=\text { Most of the time or always } \\
2=\text { Never, rarely or sometimes }\end{array}$ \\
\hline Friendship & How many close friends do you have? & $\begin{array}{l}1=0 \\
2=1 \\
3=2 \\
4=3 \text { or more }\end{array}$ & $\begin{array}{l}1=1 \text { or more } \\
2=0\end{array}$ \\
\hline
\end{tabular}

TABLE 2 | Sample description.

\begin{tabular}{|c|c|c|c|c|}
\hline Factor & $\begin{array}{l}\text { Total } \\
n(\%)\end{array}$ & $\begin{array}{l}\text { Male } \\
n(\%)\end{array}$ & $\begin{array}{c}\text { Female } \\
n(\%)\end{array}$ & $p$ Value \\
\hline \multicolumn{5}{|l|}{ Age } \\
\hline$<14$ & $472(26.6)$ & 159 (20.6) & 269 (30.0) & \multirow[t]{4}{*}{$<0.001$} \\
\hline 14 & $418(19.5)$ & $174(18.1)$ & $233(21.7)$ & \\
\hline 15 & $552(23.5)$ & $279(25.3)$ & $258(22.2)$ & \\
\hline $16+$ & $747(30.4)$ & $410(36.0)$ & $328(26.1)$ & \\
\hline \multicolumn{5}{|l|}{ Sex } \\
\hline Male & $1052(54.2)$ & \multirow[t]{2}{*}{-} & \multirow[t]{2}{*}{-} & \\
\hline Female & 1101 (45.8) & & & \\
\hline \multicolumn{5}{|l|}{ Bullied } \\
\hline Yes & $999(63.1)$ & $451(60.4)$ & $495(65.2)$ & \multirow[t]{2}{*}{0.036} \\
\hline No & $642(36.9)$ & 330 (39.6) & $290(34.8)$ & \\
\hline \multicolumn{5}{|l|}{ Fight } \\
\hline Yes & $1086(51.7)$ & 476 (49.3) & $553(54.0)$ & \multirow[t]{2}{*}{0.019} \\
\hline No & 1134 (48.3) & $561(50.7)$ & $529(46.0)$ & \\
\hline \multicolumn{5}{|c|}{ Alcohol } \\
\hline Yes & $655(46.8)$ & $267(43.1)$ & 358 (49.9) & \multirow[t]{2}{*}{0.012} \\
\hline No & $835(53.2)$ & 400 (56.9) & $407(50.1)$ & \\
\hline \multicolumn{5}{|l|}{ Activity } \\
\hline Yes & $358(18.0)$ & $150(16.0)$ & 189 (20.0) & \multirow[t]{2}{*}{0.093} \\
\hline No & $1639(82.0)$ & $776(84.0)$ & $793(80.0)$ & \\
\hline \multicolumn{5}{|c|}{ Parental supervision } \\
\hline Yes & $619(31.7)$ & $282(31.3)$ & $310(32.8)$ & \multirow[t]{2}{*}{0.996} \\
\hline No & 1238 (68.3) & $562(68.7)$ & $615(67.2)$ & \\
\hline \multicolumn{5}{|c|}{ Parental support } \\
\hline Yes & $676(35.2)$ & 297 (33.6) & $352(37.4)$ & \multirow[t]{2}{*}{0.157} \\
\hline No & $1171(64.8)$ & $551(66.4)$ & 565 (62.6) & \\
\hline \multicolumn{5}{|c|}{ Friendship } \\
\hline Yes & 1848 (84.3) & 865 (85.1) & $912(84.4)$ & \multirow[t]{2}{*}{0.966} \\
\hline No & 342 (15.7) & 154 (14.9) & 162 (15.6) & \\
\hline \multicolumn{5}{|c|}{ Psychosocial distress score } \\
\hline 0 & 391 (20.5) & 208 (23.1) & $178(18.4)$ & \multirow[t]{5}{*}{0.153} \\
\hline 1 & $678(35.1)$ & $318(34.5)$ & 334 (35.6) & \\
\hline 2 & $521(28.7)$ & $231(28.0)$ & 268 (29.2) & \\
\hline 3 & 225 (12.3) & 96 (11.3) & 115 (13.1) & \\
\hline 4 & $61(3.3)$ & $26(3.1)$ & $33(3.7)$ & \\
\hline
\end{tabular}

n, unweighted frequencies; (\%), weighted percent.

$[0.96,1.00] ; p=0.017)$ less likely to have psychosocial distress compared to females. Overall, participants of age $<14$ years were $37 \%(\mathrm{AOR}=0.63$; 95\% CI $[0.60,0.65])$ less likely to have psychosocial distress compared to participants of age 16 years or older. While male participants of age 14 years were $20 \%$
TABLE 3 | Factors associated with psychosocial distress in bivariate analysis.

\begin{tabular}{cccc}
\hline Factor & Total & Male & Female \\
& OR $(95 \% \mathrm{Cl})$ & OR $(95 \% \mathrm{Cl})$ & OR $(95 \% \mathrm{Cl})$
\end{tabular}

\begin{tabular}{lccc}
\hline Age & & & \\
$<14$ & $0.79(0.78,0.81)$ & $0.81(0.79,0.84)$ & $0.73(0.72,0.75)$ \\
14 & $1.06(1.04,1.07)$ & $0.88(0.85,0.91)$ & $1.23(1.20,1.26)$ \\
15 & $1.02(1.00,1.04)^{\mathrm{a}}$ & $1.15(1.13,1.18)$ & $0.89(0.87,0.92)$ \\
$16+$ & 1 & 1 & 1 \\
Sex & & - & - \\
Male & $0.91(0.90,0.92)$ & - & \\
Female & 1 & &
\end{tabular}

Bullied

Yes $\quad 1.65(1.63,1.67) \quad 1.49(1.47,1.52) \quad 1.85(1.81,1.89)$

No $\quad 1 \quad 11$

Fight

Yes $\quad 1.46(1.45,1.48) \quad 1.43(1.41,1.45) \quad 1.48(1.45,1.50)$

$\begin{array}{llll}\text { No } & 1 & 1 & 1\end{array}$

Alcohol

Yes $\quad 2.17(2.14,2.20) \quad 1.98(1.95,2.02) \quad 2.45(2.40,2.50)$

No $\quad 1 \quad 11$

Activity

Yes $\quad 1.36(1.35,1.38) \quad 1.29(1.26,1.31) \quad 1.91(1.84,1.97)$

No 1101

Parental supervision

Yes $\quad 1.03(1.02,1.04) \quad 0.92(0.90,0.93) \quad 1.13(1.11,1.15)$

No $\quad 1 \quad 11$

Parental support

Yes $\quad 1.05(1.04,1.06) \quad 0.95(0.94,0.97) \quad 1.13(1.11,1.15)$

No $\quad 1 \quad 1 \quad 1$

Friendship $\quad 0.95(0.93,0.96)-0.94(0.92,0.95)-0.94(0.92,0.96)$

$\begin{array}{lccc}\text { Yes } & 0.95(0.93,0.96) & 0.94(0.92,0.95) & 0.94(0.92,0.96) \\ \text { No } & 1 & 1 & 1\end{array}$

${ }^{a} p=0.048$

OR, odds ratio; (95\% Cl), 95\% confidence interval.

$(\mathrm{AOR}+0.80 ; 95 \% \mathrm{CI}[0.75,0.86])$ less likely to have psychosocial distress, female participants were $46 \%(\mathrm{AOR}=1.46 ; 95 \% \mathrm{CI}$ $[1.39,1.52])$ more likely to have psychosocial distress compared to participants of age 16 years or older.

Being bullied was significantly associated with psychosocial distress $(\mathrm{AOR}=1.26 ; 95 \% \mathrm{CI}[1.22,1.30])$ for males and $\mathrm{AOR}=1.15 ; 95 \% \mathrm{CI}[1.10,1.19])$ for females $)$. Male $(\mathrm{AOR}=1.14$; $95 \% \mathrm{CI}[1.11,1.17])$ and female $(\mathrm{AOR}=1.35 ; 95 \% \mathrm{CI}[1.31,1.39])$ 
TABLE 4 | Factors associated with psychosocial distress in multivariate analysis.

\begin{tabular}{|c|c|c|c|}
\hline Factor & $\begin{array}{c}\text { Total } \\
\text { AOR }(95 \% \mathrm{Cl})\end{array}$ & $\begin{array}{c}\text { Male } \\
\text { AOR }(95 \% \mathrm{Cl})\end{array}$ & $\begin{array}{c}\text { Female } \\
\text { AOR }(95 \% \mathrm{Cl})\end{array}$ \\
\hline \multicolumn{4}{|l|}{ Age } \\
\hline$<14$ & $0.63(0.60,0.65)$ & $0.71(0.68,0.75)$ & $0.59(0.56,0.62)$ \\
\hline 14 & $1.15(1.11,1.19)$ & $0.80(0.75,0.86)$ & $1.46(1.39,1.52)$ \\
\hline 15 & $1.03(1.00,1.06)^{a}$ & $1.02(0.98,1.07)$ & $1.01(0.97,1.06)$ \\
\hline $16+$ & 1 & 1 & 1 \\
\hline \multicolumn{4}{|l|}{ Sex } \\
\hline Male & $0.98(0.96,1.00)^{b}$ & - & - \\
\hline Female & 1 & & \\
\hline \multicolumn{4}{|l|}{ Bullied } \\
\hline Yes & $1.18(1.16,1.21)$ & $1.26(1.22,1.30)$ & $1.15(1.10,1.19)$ \\
\hline No & 1 & 1 & 1 \\
\hline \multicolumn{4}{|l|}{ Fight } \\
\hline Yes & $1.25(1.23,1.28)$ & $1.14(1.11,1.17)$ & $1.35(1.31,1.39)$ \\
\hline No & 1 & 1 & 1 \\
\hline \multicolumn{4}{|l|}{ Alcohol } \\
\hline Yes & $2.22(2.17,2.27)$ & $2.31(2.24,2.39)$ & $2.21(2.13,2.29)$ \\
\hline No & 1 & 1 & 1 \\
\hline \multicolumn{4}{|l|}{ Activity } \\
\hline Yes & $1.25(1.22,1.28)$ & $1.18(1.14,1.22)$ & $1.35(1.31,1.39)$ \\
\hline No & 1 & 1 & 1 \\
\hline \multicolumn{4}{|c|}{ Parental supervision } \\
\hline Yes & $0.84(0.83,0.86)$ & $0.69(0.67,0.71)$ & - \\
\hline No & 1 & 1 & \\
\hline \multicolumn{4}{|c|}{ Parental support } \\
\hline Yes & $1.20(1.18,1.22)$ & $1.04(1.01,1.07)$ & $1.47(1.43,1.51)$ \\
\hline No & 1 & 1 & 1 \\
\hline \multicolumn{4}{|c|}{ Friendship } \\
\hline Yes & $0.90(0.88,0.93)$ & $0.91(0.88,0.95)$ & $0.87(0.83,0.90)$ \\
\hline No & 1 & 1 & 1 \\
\hline
\end{tabular}

participants who were involved in a fight were more likely to have psychosocial distress compared to participants who were not involved in a fight. Alcohol consumption was significantly associated with psychosocial distress. Participants who consumed alcohol were about twice $(\mathrm{AOR}=2.31 ; 95 \% \mathrm{CI}[2.24,2.39]$ for males and $\mathrm{AOR}=2.21$; 95\% CI [2.13, 2.29] for females) more likely to have psychosocial distress compared to participants who did not consume alcohol.

Participants who were physically active for a period of 4-7 days in a week was more likely to have psychosocial distress $(\mathrm{AOR}=1.18 ; 95 \% \mathrm{CI}[1.14,1.22]$ for males and $\mathrm{AOR}=1.35 ; 95 \%$ CI $[1.31,1.39]$ for females).

Concerning social support, male participants with parents or guardians who most of the time or always understood their problems and worries were $4 \%(\mathrm{AOR}=1.04 ; 95 \% \mathrm{CI}[1.01,1.07])$ more likely to have psychosocial distress compared with participants with parents who never, rarely, or sometimes understood their problems or worries. Meanwhile, female participants with parents or guardians who most of the time or always understood their problems or worries were $47 \%(\mathrm{AOR}=1.47,95 \% \mathrm{CI}$ $[1.43,1.51])$ more likely to have psychosocial distress compared with participants with parents or guardians who never, rarely, or sometimes understood their problems or worries.

Male participants with parents or guardians who most of the time or always really knew what they were doing with their free time were $31 \%(\mathrm{AOR}=0.69 ; 95 \% \mathrm{CI}[0.67,0.71])$ less likely to have psychosocial distress compared with participants with parents who never, rarely, or sometimes knew what they were doing during their free time.

Having close friends was negatively associated with psychosocial distress. Overall, participants who had close friends were $10 \%$ $(\mathrm{AOR}=0.90 ; 95 \% \mathrm{CI}[0.88,0.93])$ less likely to have psychosocial distress compared with participants who did not have close friends.

\section{Discussion}

The current paper is the first one to document the prevalence and correlates for psychosocial distress among adolescents in Zambia. Analyses were stratified by sex because males and females respond to stimuli for psychosocial distress differently. In this study, psychosocial distress was detected in $15.7 \%$ of the participants $(14.4 \%$ of males and $16.8 \%$ of females). Factors that were significantly associated with psychosocial distress were age, being bullied, fight, alcohol, activity, parental support, parental supervision, and friendship.

The prevalence of $15.7 \%$ in the present study was lower than the $67.7 \%$ ( $71.2 \%$ of males and $63.3 \%$ of girls) observed in Iran (8). However, the rate in the current study was higher than the one reported in Thailand (9) of $2.5 \%$ overall $(2.0 \%$ among boys and $3.0 \%$ among girls). The differences in the rates of psychosocial distress are partly due to differences in the definitions for psychosocial distress that were used in the studies. In the Iran study, seven questions regarding worthlessness, angriness, anxiety, insomnia, confusion, sadness, and worried problems were used to screen students for psychosocial distress. Respondents with at least four of the seven items (57\% or more) in the Iranian were considered distressed. Meanwhile, in the present study and in Thailand, four mental health indicators: loneliness, anxiety or worried, sadness, and suicide plan were used to define psychosocial distress and respondents with three or four out of four items (75\% or more) were considered distressed. This difference in cut off points for distress may partly explain the observed different rates of psychosocial distress.

In the current study, while both males and females aged $<14$ years were less likely to have psychosocial distress, at the age of 14 years males continued to be less likely to have distress while females became more likely to be distressed compared to persons aged 16 years or older. Kaltiala-Heino et al. (15) observed that early pubertal timing is associated with increased mental health problems. Since females mature faster than males (16), in the early adolescence stage, females will be more likely to be psychosocially distressed compared to males in the same age group. In a related study, Ge et al. (17) observed that gender differences in depressive symptoms occurred during eighth grade and noted the interaction between the pubertal transition and psychosocial factors in depressive experiences.

The association of sex with psychosocial distress has not been consistent. The difference in rates of psychosocial distress between males and females may be due to differences in copying strategies to stressors. Lawrence et al. (18) observed that males tend to detach themselves from emotions of situations and be emotionally inhibited than females. Although in Iran, boys had a higher rate 
of distress than girls (8), the finding in the current study suggests that females had a higher risk for distress than males. Results from another study conducted in Iran (19) accord the findings from the current study that girls are more likely to have distress than boys. Several factors may contribute to the inconsistency of the association between sex and psychosocial distress and include temporal and geographical characteristics, differences in methods and tools for screening and diagnosis, difference in classification system, age groups of participants, and small sample size $(19,20)$. Overall, older participants were more likely to have psychosocial distress in the current study and this finding is similar to that obtained in Iran that reported a significantly higher mean age for students with psychosocial distress than those without (8). It is possible that younger adolescents may still be regarded as children and the community may not be as strict to them as to the older adolescents who are expected to behave like adults. Hence, older adolescents may have difficulties coping with stimuli, such as changing cultural values and societal roles. Older adolescents may also encounter dating disappointments, sexual, physical, and emotional abuses. Interventions to control distress should be targeted to younger age groups ( $<14$ years) before they have psychosocial distress.

Violence has been associated with psychosocial distress in the current study and similar findings are reported elsewhere. Among obese youth in Flanders, Belgium, bullying was associated with lower psychosocial health among obese youth (21). In Thailand, Pengpid and Peltzer (9) also reported a significant relationship between having been bullied and psychosocial distress. Participants who were involved in a fight in the present study were more likely to have psychosocial distress compared to participants who were not involved in a fight. It is possible that involvement in a fight might have induced the distress in the participants. It is also likely that participants got involved in a fight because of their temperamental state resulting from the distress. Because of the cross-sectional design of the study, we are unable to determine the pathway of the association.

Life styles-related factors have been associated with psychosocial distress in the current study. Alcohol consumption was significantly associated with psychosocial distress. Participants who consumed alcohol were about twice more likely to have psychosocial distress compared to participants who did not consume alcohol. It is not possible to determine the effect and cause in a cross-sectional study. It is possible that distressed persons may turn to drinking alcohol with the hope of "drinking away the problem" and it is also possible that alcohol consumption can lead to psychosocial distress. Furthermore, a third variable can explain the observed relationship between alcohol and psychosocial distress. Participants in the current study who were physically active were more likely to have psychosocial distress. It is unlikely that being physically active may lead to psychosocial distress. To the contrary, turning to sport may be a way to deal with the distress. Further studies considering more powerful study designs, such as case control or cohort studies, should be conducted to test the associations between life-style factors (such as alcohol consumption and physical activity) and psychosocial distress.

Concerning social support, participants with parents or guardians who most of the time or always understood their problems and worries were more likely to have psychosocial distress compared with participants with parents who never, rarely, or sometimes understood their problems or worries. It is unlikely that parental support could cause psychosocial distress in their children. To the contrary, psychosocial distress might have been the problem that could have made parents to socially support their children to deal with their problems. Male participants with parents or guardians who most of the time or always knew what they were doing with their free time were less likely to have psychosocial distress compared to male participants who had parents or guardians who did not know what they were doing with their free time. Parents should support their children and discuss their problems to avoid distress. Having close friends was protective against psychosocial distress. Close friends should always be there for their friends to share their worries and it would in turn avoid the distress.

The main limitation of this study is its cross-sectional design, which does not demonstrate the causality of association between the assumed exposure factors and psychosocial distress. We did not find records of validation of the psychosocial distress indicators that were used in the current study, apart from the fact that the indicators have been used in previous studies. Hence, we do not know the magnitude of the bias and its direction that could have been introduced in our study. The strength of present study lies in its large sample size and representativeness of the in-school-going students. The findings may not be generalized to the out-school adolescents as the occurrence of psychosocial distress may differ between in- and out-school adolescents. However, there might be minimum bias because of high-enrollment rates in Zambia. However, an overall non-response rate of $30 \%$ may cause concern with regard to the validity of our results. Our results will not be valid to the extent the non-respondents differed from the students who participated in the survey. Information on the characteristics of non-respondents was not available to enable assessment of the magnitude and direction of the bias that would have been introduced. To our knowledge, this is the first study in Zambia to examine associations for psychosocial distresses.

In conclusion, the prevalence of psychosocial distress among adolescents in Zambia appears to be common. There is a need to validate the psychosocial distress indicators that were used in the current study. If there will be need to consider more indicators to refine the definition for psychosocial distress, prevalence studies will need to be conducted to establish the magnitude of psychosocial distress and its correlates in order to generate hypotheses on psychosocial distress in our population. These hypotheses would then be tested using more powered study designs, such as cohort studies or randomized field trials, in order to accrue more evidence toward causality.

\section{Acknowledgments}

We thank the students for participating in the Zambia Global School-Based Health Survey (GSHS). We also thank the Zambian Ministries of Health and Education, the Center for Disease Control and Prevention (Atlanta, GA, USA), and the World Health Organisation, Afro Region for providing the data in the public domain, funding for data collection, and other logistical support. 


\section{References}

1. De Silva MJ, Huttly SR, Harpham T, Kenward MG. Social capital and mental health: a comparative analysis of four low income countries. Soc Sci Med (2007) 64(1):5-20. doi:10.1016/j.socscimed.2006.08.044

2. Ford T, Goodman R, Meltzer H. The British child and adolescent mental health survey 1999: the prevalence of DSM-IV disorders. J Am Acad Child Adolesc Psychiatry (2003) 42(10):1203-11. doi:10.1097/00004583-20031000000011

3. Pengpid S, Peltzer K. Prevalence and psychosocial correlates of illicit drug use among school-going adolescents in Thailand. J Soc Sci (2013) 34(3):269-75.

4. Page RM, Hall CP. Psychosocial distress and alcohol use as factors in adolescent sexual behavior among sub-Saharan African adolescents. J Sch Health (2009) 79(8):369-79. doi:10.1111/j.1746-1561.2009.00423.x

5. Hong Y, Zhang C, Li X, Liu W, Zhou Y. Partner violence and psychosocial distress among female sex workers in China. PLoS One (2013) 8(4):e62290. doi:10.1371/journal.pone.0062290

6. Henderson KM, Clark CJ, Lewis TT, Aggarwal NT, Beck T, Guo H, et al. Psychosocial distress and stroke risk in older adults. Stroke (2013) 44(2):367-72. doi:10.1161/STROKEAHA.112.679159

7. Stevenson EGJ, Greene LE, Maes KC, Ambelu A, Tesfaye YA, Rheingans R, et al. Water insecurity in 3 dimensions: an anthropological perspective on water and women's psychosocial distress in Ethiopia. Soc Sci Med (2012) 75(2):392-400. doi:10.1016/j.socscimed.2012.03.022

8. Qorbani M, Kelishadi R, Taheri E, Motlagh ME, Arzaghi SM, Ardalan G, et al. Association between psychosocial distress with cardio metabolic risk factors and liver enzymes in a nationally-representative sample of Iranian children and adolescents: the CASPIAN-III study. J Diabetes Metab Disord (2014) 13(1):44. doi:10.1186/2251-6581-13-44

9. Pengpid S, Peltzer K. Bullying and its associated factors among school-aged adolescents in Thailand. ScientificWorldJournal (2013) 2013:254083. doi:10. $1155 / 2013 / 254083$

10. Shiferaw S, Fantahun M, Bekele A. Psychosocial problems among students in preparatory school, in Dessie town, north east Ethiopia. Ethiop J Health Dev (2006) 20(1):47-54.

11. Page RM, Dennis M, Lindsay GB, Merrill RM. Psychosocial distress and substance use among adolescents in four countries: Philippines, China, Chile, and Namibia. Youth Soc (2011) 43(3):900-30. doi:10.1177/0044118X10368932

12. World Health Organization. Chronic diseases and health promotion. Global School-Based Student Health Survey (GSHS) Available from: http://www.who. int/chp/gshs/zambiadataset/en/
13. Siziya S, Muula AS, Kazembe LN, Rudatsikira E. Harmful lifestyles' clustering among sexually active in-school adolescents in Zambia. BMC Pediatr (2008) 8:6. doi:10.1186/1471-2431-8-6

14. Global School-Based Student Health Survey (GSHS). Zambia 2004 GSHS Questionnaire. Available from: http://www.who.int/chp/gshs/Zambia questionnaire_2004.pdf

15. Kaltiala-Heino R, Marttunen M, Rantanen P, Rimpelä M. Early puberty is associated with mental health problems in middle adolescence. Soc Sci Med (2003) 57:1055-64. doi:10.1016/S0277-9536(02)00480-X

16. Lim S, Han CE, Uhlhaas PJ, Kaiser M. Preferential detachment during human brain development: age- and sex-specific structural connectivity in diffusion tensor imaging (DTI) data. Cereb Cortex (2015) 25:1477-89. doi:10.1093/ cercor/bht333

17. Ge X, Conger RD, Elder GH Jr. Pubertal transition, stressful life events, and the emergence of gender differences in adolescent depressive symptoms. Dev Psychol (2001) 37:404-17. doi:10.1037/0012-1649.37.3.404

18. Lawrence J, Ashford K, Dent P. Gender differences in coping strategies of undergraduate students and their impact on self-esteem and attainment. Activ Learn High Educ (2006) 7:273-81. doi:10.1177/1469787406069058

19. Noorbala A, Yazdi SAB, Yasamy M, Mohammad K. Mental health survey of the adult population in Iran. Br J Psychiatry (2004) 184(1):70-3. doi:10.1192/bjp. 184.1.70

20. Basirnia A, Sharifi V, Mansouri N, Mesgarpour B, Mohammadi MR, Amini $\mathrm{H}$, et al. Prevalence of mental disorders among high-school students in Iran: a systematic review. Iran J Psychiatry (2009) 4(1):1-6. doi:10.1097/YCO. 0b013e328338630d

21. DeSmet A, Deforche B, Hublet A, Tanghe A, Stremersch E, De Bourdeaudhuij I. Traditional and cyberbullying victimization as correlates of psychosocial distress and barriers to a healthy lifestyle among severely obese adolescents a matched case-control study on prevalence and results from a cross-sectional study. BMC Public Health (2014) 14:224. doi:10.1186/1471-2458-14-224

Conflict of Interest Statement: The authors declare that the research was conducted in the absence of any commercial or financial relationships that could be construed as a potential conflict of interest.

Copyright (c) 2015 Siziya and Mazaba. This is an open-access article distributed under the terms of the Creative Commons Attribution License (CC BY). The use, distribution or reproduction in other forums is permitted, provided the original author(s) or licensor are credited and that the original publication in this journal is cited, in accordance with accepted academic practice. No use, distribution or reproduction is permitted which does not comply with these terms. 